\title{
Changes in Bone Turnover Markers and Bone Mass with Reducing Levels of Jumping Exercise Regimens in Female Rats
}

\author{
Foong Kiew Ooi ${ }^{* 1}$, PhD; Rabindarjeet Singh ${ }^{2}$, PhD; Harbindar Jeet Singh ${ }^{3}$, PhD
}

\author{
Authors' Affiliation: \\ 1. Sports Science Unit, Universiti \\ Sains Malaysia, Malaysia \\ 2. Advanced Medical and Dental \\ Institute, Universiti Sains \\ Malaysia, Malaysia \\ 3. Faculty of Medicine, Universiti \\ Teknologi MARA, Shah Alam, \\ Selangor, Malaysia \\ * Corresponding Author; \\ Address: Sports Science Unit, \\ School of Medical Sciences, \\ Universiti Sains Malaysia, \\ 16150 Kubang Kerian, \\ Kelantan, Malaysia \\ E-mail: fkooi@kb.usm.my
}

Received: Feb 21, 2012

Accepted: Jul 03, 2012

Key Words: Bone Biomarkers; Tibial Fat Free Dry Weight; Jumping Exercise; Rats

\begin{abstract}
Purpose: To date, little is known about the effects of a reduced level of jumping exercise regimens on bone turnover markers and mass. This study investigates the effects of different jumping exercise regimens with varying exercise loads on serum bone turnover markers and bone mass in female rats.
\end{abstract}

Methods: A total of 144 female rats aged 12 weeks, were divided into 12 groups as follows: no exercise for 8 (8S) or 32 weeks (32S), or 8 weeks of standard training program (8STP) consisting of 200 jumps per week $(200 \mathrm{~J} / \mathrm{w})$, given at 40 jumps per day (40J/d) for 5 days per week (5d/w) (8STP24E), followed by 24 weeks of exercise at loads of either $10 \mathrm{~J} / \mathrm{d}$ or $20 \mathrm{~J} / \mathrm{d}$ or $40 \mathrm{~J} / \mathrm{d}$, for either $5 \mathrm{~d} / \mathrm{w}$, or $3 \mathrm{~d} / \mathrm{w}$, or $1 \mathrm{~d} / \mathrm{w}$. Serum osteocalcin, alkaline phosphatase, C-terminal telopeptide of type 1 collagen (1CTP) concentrations, and tibial fat free dry weight were measured.

Results: Tibial mass was significantly higher in 8STP than 8S. No changes were evident in serum markers of bone turnover parameters after 8STP. Significant increases in tibial mass were observed in rats that continued to exercise at workloads of $30 \mathrm{~J} / \mathrm{w}$ and above after 8STP. Serum alkaline phosphatase concentrations increase whereas serum 1CTP concentrations decrease in rats given workloads of $40 \mathrm{~J} / \mathrm{w}$ and above.

Conclusions: It appears, an exercise load of $30 \mathrm{~J} / \mathrm{w}$, i.e. $10 \mathrm{~J} / \mathrm{d}$ for $3 \mathrm{~d} / \mathrm{w}$, was the minimum level of continuous exercise load that was required to maintain the 8STP-induced bone gains. In addition, significant increases in bone mass in young rats following 8STP might not always be reflected by changes in serum levels of osteocalcin, alkaline phosphatase and 1CTP.

Asian Journal of Sports Medicine, Volume 3 (Number 4), December 2012, Pages: 225-232

\section{INTRODUCTION}

$\mathrm{T}$ he skeleton is a very active organ metabolically as it is in a continuous dynamic remodeling process; maintaining a tightly coupled balance between resorption of old bone and formation of new bone ${ }^{[1]}$. The balance between bone resorption and formation is influenced by age and the level of strain on the bone generated by muscle contraction during movements. Specific biochemical markers of bone turnover that allow us to estimate bone metabolic processes and have been established, which are useful parameters in assessing changes in bone turnover ${ }^{[1-4]}$.
It has been well recognized that exercise of appropriate intensity and frequency stimulates mineralization and therefore bone gains ${ }^{[5,6]}$. It is also equally well recognized that cessation of exercise causes a loss in exercise-induced bone gains in humans ${ }^{[7,8]}$ and animals ${ }^{[9,10]}$. Thus, continuous exercise is needed to maintain exercise-induced bone gains. Currently, there is little information on the minimum quantum of continuous exercise that is required to maintain exercise induced gains in bone physical properties, and equally significantly, it is also unknown if this could be ascertained through the markers of bone metabolism. The present study, therefore, investigated 
the impact of a series of exercise loads that were lower than the exercise load used to induce bone gains on serum biochemical markers of bone turnover in female rats over a period of 24 weeks. The exercise load used to induce initial bone gains consisted of an 8-week jumping exercise program consisting of 40 jumps per day at 5 days per week. It is hoped that results obtained from this study could help design sub-maximal exercise programs, which could be used for developing age-specific exercise regimens, by formulating guidelines for the enhancement and maintenance of bone health in human beings.

\section{METHODS AND SUBJECTS}

\section{Animals Grouping and Exercise Regimen:}

One hundred and twenty, 12-week old female Wistar Kyoto rats with mean initial body weight of $179.9 \pm$ $10.8 \mathrm{~g}$, were randomized into twelve weight matched groups, with ten rats per group. The groups were as follows: 8 weeks of exercise with a standard training program of 40 jumps per day for 5 days per week (8STP); 8 weeks sedentary control $(8 \mathrm{~S})$ (S, free cage activity only); 32 weeks sedentary control (32S); and nine groups of rats given 8 weeks of standard training program followed by 24 weeks of continuous exercise (8STP24E), with either maintaining or decreasing the frequency of training days from 5 days per week $(5 d / w)$ to $3 d / w$ or $1 d / w$, and by either maintaining or decreasing the intensity of training from 40 jumps per day $(40 \mathrm{~J} / \mathrm{d}$ ) to $20 \mathrm{~J} / \mathrm{d}$ or $10 \mathrm{~J} / \mathrm{d}$ (Table 1 ).

These nine exercise groups with different exercise regimens were identified as $8 \mathrm{STP} 24 \mathrm{E}(5 \mathrm{~d} / \mathrm{w}, 40 \mathrm{~J} / \mathrm{d})$ $(200 \mathrm{~J} / \mathrm{w}) ; 8$ STP24E $(3 \mathrm{~d} / \mathrm{w}, 40 \mathrm{~J} / \mathrm{d})(120 \mathrm{~J} / \mathrm{w}) ; 8 \mathrm{STP} 24 \mathrm{E}$ $(5 \mathrm{~d} / \mathrm{w}, 20 \mathrm{~J} / \mathrm{d})(100 \mathrm{~J} / \mathrm{w}) ; 8$ STP24E $(3 \mathrm{~d} / \mathrm{w}, 20 \mathrm{~J} / \mathrm{d})(60 \mathrm{~J} / \mathrm{w})$; 8 STP24E $(5 \mathrm{~d} / \mathrm{w}, 10 \mathrm{~J} / \mathrm{d})(50 \mathrm{~J} / \mathrm{w}) ; 8$ STP24E $(1 \mathrm{~d} / \mathrm{w}, 40 \mathrm{~J} / \mathrm{d})$ $(40 \mathrm{~J} / \mathrm{w}) ; \quad 8 \mathrm{STP} 24 \mathrm{E} \quad(3 \mathrm{~d} / \mathrm{w}, 10 \mathrm{~J} / \mathrm{d})(30 \mathrm{~J} / \mathrm{w}) ; \quad 8 \mathrm{STP} 24 \mathrm{E}$ $(1 \mathrm{~d} / \mathrm{w}, 20 \mathrm{~J} / \mathrm{d})(20 \mathrm{~J} / \mathrm{w}) ; \quad 8$ STP24E $\quad(1 \mathrm{~d} / \mathrm{w}, 10 \mathrm{~J} / \mathrm{d})(10 \mathrm{~J} / \mathrm{w})$ according to number of jumps per week. The jumping height used in this study was $40 \mathrm{~cm}$. All animals were housed in cages measuring $55 \mathrm{~cm} \times 33 \mathrm{~cm} \times 19 \mathrm{~cm}$ with five animals per cage. They were exposed to a constant 12:12 light/dark cycle and had ad libitum access to water and chow (Gold Coin, Port Klang, Malaysia) throughout the study. Rats in $8 \mathrm{~S}$ and $8 \mathrm{STP}$ groups were euthanized at the end of the eighth week. Rats in 32S, $8 \mathrm{STP} 24 \mathrm{~S}$ and in the nine exercised groups with different exercise regimens (8STP24E) were euthanized at the end of thirty-two weeks (Table 1). After recording their final body weight (Ohaus Navigator $^{\mathrm{TM}}$ Balance, U.S.A.), the rats were anaesthetized with diethyl ether and then decapitated using an animal guillotine (Scientific Research Instrument, U.K.) for collection of blood for subsequent blood biochemical analysis. Tibial bones of the rats' hind limbs were collected for measurement of bone mass. The experimental protocol was approved by the Research Ethics Committee of Universiti Sains Malaysia.

\section{Jump Training:}

Jump training was carried out using a previously described protocol ${ }^{[4]}$. Briefly, each rat in the jumping exercise groups was placed on a metal grid at the bottom of a special wooden box measuring $30.5 \times 30.5$ x $40 \mathrm{~cm}$ in length, width and height respectively. The jumping exercise was initiated by applying an electrical current to the wired floor (electrical grid) of the box through a stimulator. When stimulated, each rat jumped from the floor of the box to catch the top edge of the box with its forepaws. The rat was then immediately returned by hand to the floor of the box to repeat the procedure. The time required per jump was about 4 seconds. After a few days of training, the rats jumped without electrical stimulation. Rats in the sedentary groups were not given any electrical stimulus but to mimic the stress induced by handling before and after jumping exercise, the sedentary rats were also similarly handled for 5 days per week.

\section{Blood Collection and Bone Mass Measurement:}

At the end of the experimental period, the rats were anaesthetized, one at a time, by placing them for 2-3 minutes in a desiccated jar containing $5 \mathrm{ml}$ of diethyl ether before being decapitated using a small animal guillotine (Scientific Research Instrument, U.K.). Blood was collected from the decapitation site into a $10 \mathrm{ml}$ test-tube through a funnel and left aside for one hour to ensure complete clotting. Serum was then obtained by centrifugation (15 minutes, 3000 RPM, $4^{\circ} \mathrm{C}$; Hettich-Rotina 46RS, Germany), after which the serum was divided into three equal portions (approximately $0.5 \mathrm{ml}$ per portion) and stored at $-80^{\circ} \mathrm{C}$ 
Table 1: The experimental groups, including the training and sedentary periods, and age of the rats

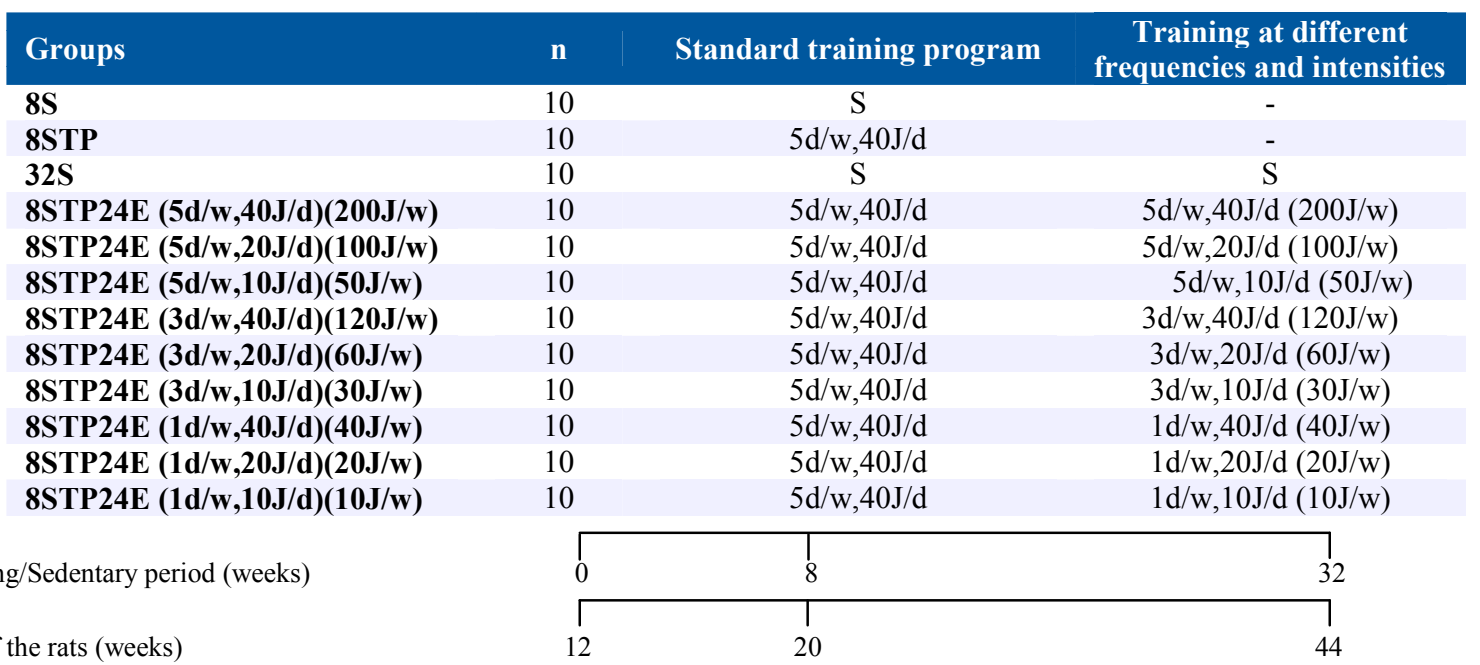

Training/Sedentary period (weeks)

Age of the rats (weeks)

$\mathrm{S}=$ Sedentary $/ / 8 \mathrm{~S}=8$ weeks sedentary control $\quad / / \quad 8 \mathrm{STP}=8$ weeks of exercise with standard training program for $5 \mathrm{~d} / \mathrm{w}$ at $40 \mathrm{~J} / \mathrm{d}$

$32 \mathrm{~S}=32$ weeks sedentary control // $\mathrm{E}=$ Exercise $/ / \quad \mathrm{J} / \mathrm{w}=$ Number of jumps per week $/ / \quad \mathrm{d} / \mathrm{w}=$ Number of days per week

$\mathrm{J} / \mathrm{d}=$ Number of jumps per day

$8 \mathrm{STP} 24 \mathrm{E}(5 \mathrm{~d} / \mathrm{w}, 40 \mathrm{~J} / \mathrm{d})(200 \mathrm{~J} / \mathrm{w})=8$ weeks of exercise with standard training program then followed by $200 \mathrm{jumps}$.week ${ }^{-1}$ for $24 \mathrm{weeks}$ of $5 \mathrm{~d} / \mathrm{w}$ at $40 \mathrm{~J} / \mathrm{d}$ $8 \mathrm{STP} 24 \mathrm{E}(5 \mathrm{~d} / \mathrm{w}, 20 \mathrm{~J} / \mathrm{d})(100 \mathrm{~J} / \mathrm{w})=8$ weeks of exercise with standard training program then followed by 100 jumps.week ${ }^{-1}$ for 24 weeks of $5 \mathrm{~d} / \mathrm{w}$ at $20 \mathrm{~J} / \mathrm{d}$ $8 \mathrm{STP} 24 \mathrm{E}(5 \mathrm{~d} / \mathrm{w}, 10 \mathrm{~J} / \mathrm{d})(50 \mathrm{~J} / \mathrm{w})=8$ weeks of exercise with standard training program then followed by 50 jumps.week ${ }^{-1}$ for $24 \mathrm{weeks}$ of $5 \mathrm{~d} / \mathrm{w}$ at $10 \mathrm{~J} / \mathrm{d}$ $8 \mathrm{STP} 24 \mathrm{E}(3 \mathrm{~d} / \mathrm{w}, 40 \mathrm{~J} / \mathrm{d})(120 \mathrm{~J} / \mathrm{w})=8$ weeks of exercise with standard training program then followed by 120 jumps.week ${ }^{-1}$ for $24 \mathrm{weeks}$ of $3 \mathrm{~d} / \mathrm{w}$ at $40 \mathrm{~J} / \mathrm{d}$ $8 \mathrm{STP} 24 \mathrm{E}(3 \mathrm{~d} / \mathrm{w}, 20 \mathrm{~J} / \mathrm{d})(60 \mathrm{~J} / \mathrm{w})=8$ weeks of exercise with standard training program then followed by 60 jumps.week ${ }^{-1}$ for $24 \mathrm{weeks}$ of $3 \mathrm{~d} / \mathrm{w}$ at $20 \mathrm{~J} / \mathrm{d}$ $8 \mathrm{STP} 24 \mathrm{E}(3 \mathrm{~d} / \mathrm{w}, 10 \mathrm{~J} / \mathrm{d})(30 \mathrm{~J} / \mathrm{w})=8$ weeks of exercise with standard training program then followed by 30 jumps.week ${ }^{-1}$ for $24 \mathrm{weeks}$ of $3 \mathrm{~d} / \mathrm{w}$ at $10 \mathrm{~J} / \mathrm{d}$ $8 \mathrm{STP} 24 \mathrm{E}(1 \mathrm{~d} / \mathrm{w}, 40 \mathrm{~J} / \mathrm{d})(40 \mathrm{~J} / \mathrm{w})=8$ weeks of exercise with standard training program then followed by 40 jumps.week ${ }^{-1}$ for $24 \mathrm{weeks}$ of $1 \mathrm{~d} / \mathrm{w}$ at $40 \mathrm{~J} / \mathrm{d}$ $8 \mathrm{STP} 24 \mathrm{E}(1 \mathrm{~d} / \mathrm{w}, 20 \mathrm{~J} / \mathrm{d})(20 \mathrm{~J} / \mathrm{w})=8$ weeks of exercise with standard training program then followed by 20 jumps.week ${ }^{-1}$ for 24 weeks of $1 \mathrm{~d} / \mathrm{w}$ at $20 \mathrm{~J} / \mathrm{d}$ $\left[8 \mathrm{STP} 24 \mathrm{E}(1 \mathrm{~d} / \mathrm{w}, 10 \mathrm{~J} / \mathrm{d})(10 \mathrm{~J} / \mathrm{w})=8\right.$ weeks of exercise with standard training program then followed by 10 jumps.week ${ }^{-1}$ for $24 \mathrm{weeks}$ of $1 \mathrm{~d} / \mathrm{w}$ at $10 \mathrm{~J} / \mathrm{d}$

(Heto Ultra Freezer 3410, Denmark) until analysis at a later date.

The tibiae were dissected from the right hind limb. Jumping in these animals depends on forces generated by the hind limb, thus the hind limb tibiae were selected in this study ${ }^{[11]}$. The tibiae were then wrapped in saline-soaked gauze pads, to prevent dehydration, and put into labelled plastic bags and stored at $-80^{\circ} \mathrm{C}$ for the measurement of bone mass at a later date. For bone mass measurement, the harvested tibiae were immersed in a mixture of chloroform and methanol solvent ( $2: 1$ by volume respectively) for one week to remove the fat from the bones ${ }^{[12-14]}$. Following this the bones were oven dried at $80^{\circ} \mathrm{C}$ for 24 hours (Isuzu Model 2-2020, Isuzu Seisakusho Co., Ltd., Japan). After drying, the bone weight (to the nearest $0.01 \mathrm{mg}$ ) was determined on an electronic balance (ER-180A, A\&D Company, Japan).

\section{Blood biochemical analysis:}

Serum concentrations of osteocalcin and alkaline phosphatase (Alk-Ph) (markers of bone formation) and C-terminal telopeptide of type 1 collagen/1CTP (marker of bone resorption) were estimated in the terminal blood. Serum Alk-Ph was analyzed colorimetrically (Hitachi Automatic Analyzer 912, Bohringer Mannheim, Germany) using commercially available reagent kits (Roche Diagnostics $\mathrm{GmbH}$, Germany). The intra-assay coefficient of variation (CV) values of the assay kits were $0.67 \%, 0.47 \%$, $0.45 \%$ and $0.61 \%$ at $63.3,84.1,214.7$ and $304.7{\mathrm{U} .1^{-1}}^{-1}$ of serum Alk-Ph concentration respectively, and the inter-assay $\mathrm{CV}$ values were $0.67 \%, 0.27 \%, 0.47 \%$ and $0.67 \%$ at $62.0,85.6,210.6$ and $298.3 \mathrm{U}^{-1}$ of serum Alk-Ph concentration respectively.

Serum osteocalcin was analyzed using a commercially available enzyme-linked immunosorbent assay kit (Nordic Bioscience Diagnostics Rat-MID ${ }^{\mathrm{TM}}$ Osteocalcin ELISA, Denmark) and the concentration was determined using a photometric microplate reader (Molecular Devices; Versa ${ }_{\max }$ tunable microplate reader, U.S.A.). The intra-assay coefficient of variation 
(CV) values of the assay kits were 3.6\%, 5.0\% and $3.4 \%$ at 152,215 and $948 \mathrm{ng} \cdot \mathrm{ml}^{-1}$ of serum osteocalcin concentration respectively, and the inter-assay $\mathrm{CV}$ values were $6.6 \%, 5.5 \%$ and $7.7 \%$ at 152,215 and 948 ng.ml ${ }^{-1}$ of serum osteocalcin concentration respectively.

Serum C-terminal telopeptide of type 1 collagen (1CTP) was analysed using a commercially available enzymeimmunoassay kit (Orion Diagnostica UniQ 1CTP EIA, Finland), and the concentration was determined by a photometric microplate reader (Molecular Devices; Versa $a_{\max }$ tunable microplate reader, U.S.A.). The intra-assay coefficient of variation (CV) values of the assay kits were $8.1 \%, 8.9 \%$ and $7.6 \%$ at $5.6,13.7$ and $26.4 \mu \mathrm{g} .1^{-1}$ of serum 1CTP concentration respectively, and the inter-assay $\mathrm{CV}$ values were $7.5 \%, 9.8 \%$ and $6.4 \%$ at $7.1,13.1$ and $28.2 \mu \mathrm{g} .1^{-1}$ of serum 1CTP concentration respectively.

\section{Statistical Analysis:}

Statistical tests contained in the Statistical Package for Social Sciences (SPSS) Version 10.0 were used for the statistical analysis. One-way analysis of variance (ANOVA) was performed to determine the significance of the differences between groups. When the one-way ANOVA revealed a significant difference, post hoc (least significant difference test) was used to determine the differences between specific means. All data are reported as mean \pm standard deviation (SD).

\section{RESULTS}

During the experimental period, one of the rats in group $8 \mathrm{STP} 24 \mathrm{E}(3 \mathrm{~d} / \mathrm{w}, 10 \mathrm{~J} / \mathrm{w} ; 30 \mathrm{~J} / \mathrm{w})$ died of an unidentified cause, and 119 rats were therefore left for data analysis.

\section{Body weight:}

Initial mean body weight of all the experimental rats was $179.9 \pm 10.8$ g. Post hoc tests revealed no significant differences in initial body weight between all the experimental groups as all the rats were weight and age-matched. The final mean body weights of the rats in $8 \mathrm{~S}$ and $8 \mathrm{STP}$ were $225.2 \pm 21.3$ and $227.3 \pm$ $16.8 \mathrm{~g}$ respectively, and no significant difference was observed in final mean body weight between these two groups. Furthermore, no statistically significant differences in final mean body weight were observed between $32 \mathrm{~S}$ group and all the other nine exercised groups (8STP24E). Final mean body weight of rats in $32 \mathrm{~S}$ and 8STP24E groups was $269.1 \pm 18.7 \mathrm{~g}$, and the final body weights of the $32 \mathrm{~S}$ and $8 \mathrm{STP} 24 \mathrm{E}$ groups ranged from $257.8 \pm 15.1$ to $277.1 \pm 17.3 \mathrm{~g}$.

\section{Bone mass:}

Tibial mass was significantly higher in 8STP than 8S (Table 2). In rats that were further trained for 24 weeks with different exercise regimens after 8STP, mean tibial mass were significantly higher $(P<0.01)$ in all the rats given 24 weeks of jumping exercise that ranged from $30 \mathrm{~J} / \mathrm{w}$ to $200 \mathrm{~J} / \mathrm{w}$ generally.

\section{Blood bone turnover markers:}

Mean concentrations of all the serum parameters of the various groups are presented in Table 2. No significant differences were evident in serum osteocalcin concentrations between the exercised rats and their respective age-matched sedentary controls. Similarly, no significant differences were evident in serum Alk$\mathrm{Ph}$ concentrations between the exercised rats and their respective sedentary controls except for rats receiving exercise loads of 40, 50 and 200J/w. Nevertheless, nonsignificant higher values of serum Alk-Ph were evident in groups given $100 \mathrm{~J} / \mathrm{w}$ and $120 \mathrm{~J} / \mathrm{w}$ when compared to $32 \mathrm{~S}$.

There was no significant difference in serum 1CTP between 8STP and their age-matched sedentary control (8S). Serum 1CTP concentrations, however, were significantly lower $(P<0.001)$ in all rats given 24 weeks of jumping exercise that ranged from $40 \mathrm{~J} / \mathrm{w}$ to $200 \mathrm{~J} / \mathrm{W}$ when compared to that in the sedentary control $(32 \mathrm{~S})$. Fig. 1 shows the relationship between tibial mass, serum Alk-Ph and 1CTP concentrations among the various exercised groups. Bone mass and serum formation marker increased, while serum bone resorption marker decreased during exercise with increasing exercise load.

\section{DISCUSSION}

Bone is always in a continuous dynamic remodelling process involving resorption of old bone and formation 
Table 2: Mean tibial mass, serum osteocalcin, Alk-Ph and 1CTP concentrations in the exercise and sedentary groups

\begin{tabular}{|c|c|c|c|c|}
\hline \multirow{2}{*}{ Groups } & \multirow{2}{*}{ Tibial mass(mg) } & \multicolumn{3}{|c|}{ Serum Concentration } \\
\hline & & Osteocalcin (ng.mL ${ }^{-1}$ ) & Alk-Ph (U.L'-1) & 1CTP $\left(\mu \mathrm{g} . \mathrm{L}^{-1}\right)$ \\
\hline $8 S$ & $393.25(42.49)$ & $124.45(57.13)$ & $177.25(31.29)$ & $1.01(0.53)$ \\
\hline 8STP & $424.47(27.57)$ * & $151.14(48.03)$ & $189.00(36.46)$ & $1.20(0.52)$ \\
\hline $32 \mathrm{~S}$ & $430.04(30.00)$ & $66.01(30.58)$ & $119.70(29.12)$ & $1.08(0.48)$ \\
\hline $8 S T P 24 E(1 d / w, 10 J / d)(10 J / w)$ & $444.67(28.25)$ & $62.68(18.65)$ & $113.89(18.71)$ & $0.96(0.32)$ \\
\hline 8STP24E(1d/w,20J/d)(20J/w) & $435.04(33.94)$ & $76.79(40.95)$ & $118.14(15.20)$ & $0.60(0.28)^{\#}$ \\
\hline $8 S T P 24 E(3 d / w, 10 J / d)(30 J / w)$ & $493.53(25.46)$ & $83.89(43.60)$ & $110.00(37.70)$ & $0.97(0.08)$ \\
\hline $8 S T P 24 E(1 d / w, 40 J / d)(40 J / w)$ & $455.66(24.56)$ & $88.27(56.31)$ & $147.40(34.59)$ \# & $0.33(0.10) *$ \\
\hline $8 \mathrm{STP} 24 \mathrm{E}(5 \mathrm{~d} / \mathrm{w}, 10 \mathrm{~J} / \mathrm{d})(50 \mathrm{~J} / \mathrm{w})$ & $476.24(28.90)^{\dagger}$ & $4.68(29.34)$ & $146.50(26.56)$ \# & $0.31(0.14)^{*}$ \\
\hline $8 S T P 24 E(3 d / w, 20 J / d)(60 J / w)$ & $484.92(20.71)^{\dagger}$ & $70.74(38.01)$ & $110.00(23.80)$ & $0.18(0.14) *$ \\
\hline $8 S T P 24 E(5 d / w, 20 J / d)(100 J / w)$ & $482.62(37.61)^{\dagger}$ & $61.16(20.06)$ & $130.60(33.64)$ & $0.18(0.15) *$ \\
\hline $8 S T P 24 E(3 d / w, 40 J / d)(120 J / w)$ & $479.06(31.93)^{\dagger}$ & $72.21(26.92)$ & $125.50(24.94)$ & $0.13(0.07) *$ \\
\hline $8 \mathrm{STP} 24 \mathrm{E}(5 \mathrm{~d} / \mathrm{w}, 40 \mathrm{~J} / \mathrm{d})(200 \mathrm{~J} / \mathrm{w})$ & $497.51(50.09) *$ & $86.48(14.57)$ & $152.40(32.77)^{+}$ & $0.17(0.10) *$ \\
\hline
\end{tabular}

$* P<0.05$ compared to age-matched sedentary controls $(8 \mathrm{~S})$.

${ }^{\#} P<0.05 ;{ }^{\dagger} P<0.01 ;{ }^{*} P<0.001$ compared to age-matched sedentary controls (32S)

1CTP: C-terminal telopeptide of type 1 collagen // Alk-Ph: alkaline phosphatase $/ / \quad \mathrm{S}=$ Sedentary $/ / 8 \mathrm{~S}=8$ weeks sedentary control // $8 \mathrm{STP}=8$ weeks of exercise with standard training program for $5 \mathrm{~d} / \mathrm{w}$ at $40 \mathrm{~J} / \mathrm{d} \quad / / \quad 32 \mathrm{~S}=32$ weeks sedentary control $/ / \quad \mathrm{E}=\mathrm{Exercise} \quad / /$

$\mathrm{J} / \mathrm{w}=$ Number of jumps per week $/ / \quad \mathrm{d} / \mathrm{w}=$ Number of days per week $\quad / / \quad \mathrm{J} / \mathrm{d}=$ Number of jumps per day

$8 \mathrm{STP} 24 \mathrm{E}(1 \mathrm{~d} / \mathrm{w}, 10 \mathrm{~J} / \mathrm{d})(10 \mathrm{~J} / \mathrm{w})=8$ weeks of exercise with standard training program then followed by 10 jumps.week ${ }^{-1}$ for $24 \mathrm{weeks}$ of $1 \mathrm{~d} / \mathrm{w}$ at $10 \mathrm{~J} / \mathrm{d}$ $8 \mathrm{STP} 24 \mathrm{E}(1 \mathrm{~d} / \mathrm{w}, 20 \mathrm{~J} / \mathrm{d})(20 \mathrm{~J} / \mathrm{w})=8$ weeks of exercise with standard training program then followed by 20 jumps.week ${ }^{-1}$ for $24 \mathrm{weeks}$ of $1 \mathrm{~d} / \mathrm{w}$ at $20 \mathrm{~J} / \mathrm{d}$ $8 \mathrm{STP} 24 \mathrm{E}(3 \mathrm{~d} / \mathrm{w}, 10 \mathrm{~J} / \mathrm{d})(30 \mathrm{~J} / \mathrm{w})=8$ weeks of exercise with standard training program then followed by 30 jumps.week ${ }^{-1}$ for 24 weeks of $3 \mathrm{~d} / \mathrm{w}$ at $10 \mathrm{~J} / \mathrm{d}$ $8 \mathrm{STP} 24 \mathrm{E}(1 \mathrm{~d} / \mathrm{w}, 40 \mathrm{~J} / \mathrm{d})(40 \mathrm{~J} / \mathrm{w})=8$ weeks of exercise with standard training program then followed by 40 jumps.week ${ }^{-1}$ for $24 \mathrm{weeks}$ of $1 \mathrm{~d} / \mathrm{w}$ at $40 \mathrm{~J} / \mathrm{d}$ $8 \mathrm{STP} 24 \mathrm{E}(5 \mathrm{~d} / \mathrm{w}, 10 \mathrm{~J} / \mathrm{d})(50 \mathrm{~J} / \mathrm{w})=8$ weeks of exercise with standard training program then followed by 50 jumps.week ${ }^{-1}$ for $24 \mathrm{weeks}$ of $5 \mathrm{~d} / \mathrm{w}$ at $10 \mathrm{~J} / \mathrm{d}$ $8 \mathrm{STP} 24 \mathrm{E}(3 \mathrm{~d} / \mathrm{w}, 20 \mathrm{~J} / \mathrm{d})(60 \mathrm{~J} / \mathrm{w})=8$ weeks of exercise with standard training program then followed by 60 jumps.week ${ }^{-1}$ for $24 \mathrm{weeks}$ of $3 \mathrm{~d} / \mathrm{w}$ at $20 \mathrm{~J} / \mathrm{d}$ $8 \mathrm{STP} 24 \mathrm{E}(5 \mathrm{~d} / \mathrm{w}, 20 \mathrm{~J} / \mathrm{d})(100 \mathrm{~J} / \mathrm{w})=8$ weeks of exercise with standard training program then followed by 100 jumps.week ${ }^{-1}$ for $24 \mathrm{weeks}$ of $5 \mathrm{~d} / \mathrm{w}$ at $20 \mathrm{~J} / \mathrm{d}$ $8 \mathrm{STP} 24 \mathrm{E}(3 \mathrm{~d} / \mathrm{w}, 40 \mathrm{~J} / \mathrm{d})(120 \mathrm{~J} / \mathrm{w})=8$ weeks of exercise with standard training program then followed by 120 jumps.week ${ }^{-1}$ for $24 \mathrm{weeks}$ of $3 \mathrm{~d} / \mathrm{w}$ at $40 \mathrm{~J} / \mathrm{d}$ $8 \mathrm{STP} 24 \mathrm{E}(5 \mathrm{~d} / \mathrm{w}, 40 \mathrm{~J} / \mathrm{d})(200 \mathrm{~J} / \mathrm{w})=8$ weeks of exercise with standard training program then followed by 200 jumps.week ${ }^{-1}$ for 24 weeks of $5 \mathrm{~d} / \mathrm{w}$ at $40 \mathrm{~J} / \mathrm{d}$

of new bone ${ }^{[1]}$, and specific biochemical markers of bone have been commonly used in evaluating changes in bone turnover ${ }^{[1-4]}$. To date, most measurements of markers of bone turnover have been restricted to shortterm interventions, such as acute or short-term effects of a single bout of exercise ${ }^{[15-18]}$ or to cross-sectional studies ${ }^{[19-21]}$. Thus the longitudinal approach with 32 weeks of continuous jumping exercise used in the present study to examine the effect of long-term exercise in female rats as they age provides an additional picture of the effect of long-term exercise on bone turnover. In addition it also examines the minimum level of physical activity required to maintain bone gains through the estimation of bone formation and resorption markers.

The major findings of this study include (i) a gain in tibial mass that is significantly greater in rats given eight weeks of jumping exercise (8STP) compared to gains in age-matched sedentary controls (8S), (ii) significantly greater increase in mean tibial mass in rats that continued to receive exercise training for a further 24 weeks (Table 2), (iii) the increase was greater if the exercise was given 3 times per week instead of just once per week, and (iv) serum 1CTP levels were significantly lower in rats receiving exercise loads of $40 \mathrm{~J} / \mathrm{w}$ and above (Table 2). Serum 1CTP levels also correlated negatively with increasing exercise loads at up to about $120 \mathrm{~J} / \mathrm{w}$ after which it seems to plateau (Fig. 1). The present results indicate that the minimum level of exercise load required to elicit beneficial effects on bone mass after elevation of bone mass induced by $8 \mathrm{STP}$ was estimated at $30 \mathrm{~J} / \mathrm{w}$, that is $10 \mathrm{~J} / \mathrm{d}$ for $3 \mathrm{~d} / \mathrm{w}$, i.e. given in three divided doses in a week. This study confirms observations of previous studies in humans ${ }^{[22-25]}$ and animals ${ }^{[26,27]}$, showing that bone mineral content and mass could be maintained with follow-up exercise loads that are lower than those initially used to induce the gains. In the present study, investigation of cellular mechanism responsible for the bone gains was unfortunately not carried out. However, it is speculated that bone cells might behave as a neuronal network ${ }^{[28]}$ and incorporation of memories of mechanical loading events during growth and development might strongly influence bone biology. The acquired long-term memory of a mechanical loading environment might influence the responsiveness of bone tissue to external stimuli. That is, the history of weight bearing activities imparts long-term 

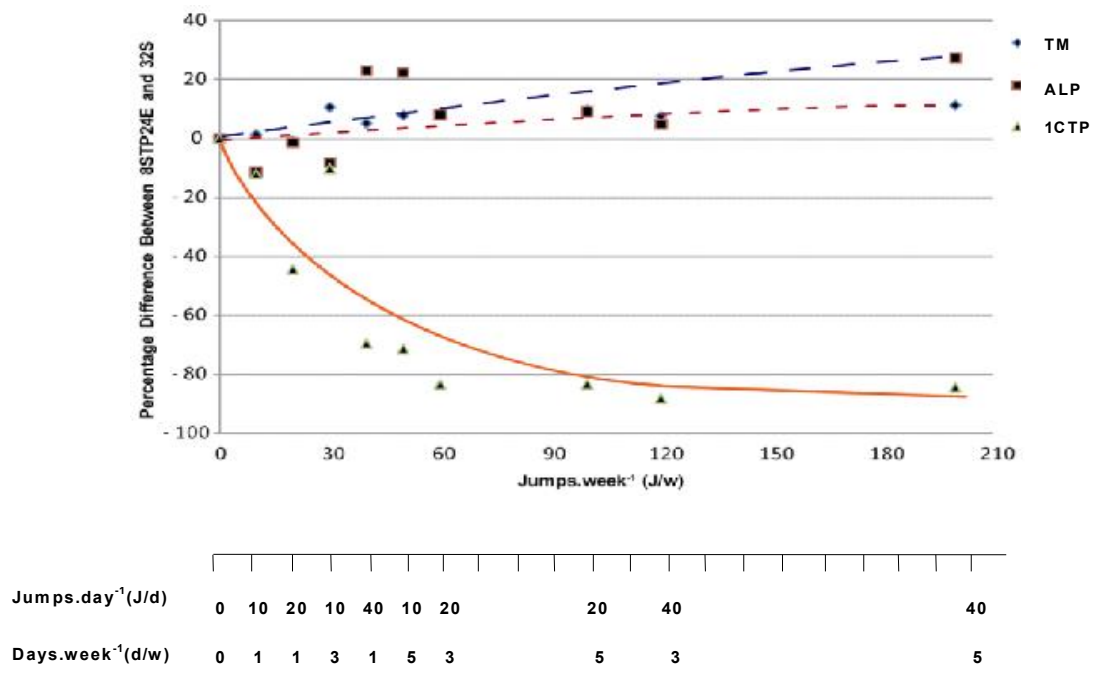

Fig. 1: Plots of the percentage differences in mean tibial mass (TM), serum alkaline phosphatase (ALP) and C-terminal telopeptide of type 1 collagen (1CTP) concentrations between exercised rats (8STP24E) and their respective age-matched sedentary control.

cellular memory to the bone cell network. The above explanation may be applicable to the present observation that after 8 weeks of jumping exercise of $40 \mathrm{~J} / \mathrm{d}$ at a frequency of $5 \mathrm{~d} / \mathrm{w}$, during the growing period, the reduced level of continuous exercise at 10 $\mathrm{J} / \mathrm{d}$ at a frequency of $3 \mathrm{had}$ the ability to maintain the exercise-induced gain in bone mass in female rats. It is speculated that bones of the rats might respond to low and reduced level of mechanical loading after acquiring long-term cellular memory on pre-existing mechanical loading. In the present study, unfortunately we are unable to provide any data on the primary measurement of bone mineral density. Additionally, bone responses at cellular level and genetic factors were also not determined. It is suggested that future studies with measurement of bone mineral density and investigation at cellular level and genetic factors could be carried out to clarify the precise underlying mechanism of the present findings.

Another finding in the 20 week-old young rats that performed 8STP was that no significant changes in bone turnover markers were observed even though there was a significant increase in bone mass when compared to the sedentary control (8S)(Table 1). One possible explanation for the absence of significant changes in blood osteocalcin, Alk-Ph and 1CTP concentrations after exercise in young rats in our study and in other exercise studies in young mice ${ }^{[29-32]}$ might be due to the age of the rats or the localised effect of jumping exercise, which is limited to the hind limbs only, although the latter reason is somewhat contradicted by the finding of lower serum 1CTP concentrations following further continuous exercise (Table 2 and Fig. 1). It is possible the changes in blood parameters might have been too small to be detected, even though serum turnover markers are supposed to reflect the overall level of bone turnover of the entire skeleton ${ }^{[33-35]}$. In agreement with the present finding, absence of significant changes in blood bone turnover markers was also reported following an 18-month highimpact training in young male gymnasts ${ }^{[36]}$, and another recent study following 6 weeks of aerobic dance exercise in young females ${ }^{[37]}$. The use of blood bone turnover markers in these types of exercise protocols in young animals and humans therefore remains uncertain and debatable.

Interestingly, when the rats were further trained for additional 24 weeks after 8 weeks of exercise, two positive relationships could be observed in bone mass and blood formation markers in rats with exercise loads of $40 \mathrm{~J} / \mathrm{w}(40 \mathrm{~J} / \mathrm{d}, 1 \mathrm{~d} / \mathrm{w})$ and above. First, the tibial mass and serum Alk-Ph concentration increased with increasing exercise load (Table 2, Fig. 1). This positive correlation was evident when the differences in both tibial mass and serum Alk-Ph between exercised rats and their age-matched sedentary controls were plotted 
on a logarithmic curve fit against workload $(\mathrm{J} / \mathrm{w})$. The increasing levels of bone mass and serum alkaline Alk$\mathrm{Ph}$ with exercise load may indicate the presence of net bone formation in these rats. Secondly, a negative relationship was observed in serum 1CTP, which reflects decreased bone resorption with increasing workload. Here, serum 1CTP concentration decreased with increasing exercise loads (Table 2, Fig. 1). The present findings show that when bones are mechanically loaded during exercise, bone resorption decreases and bone formation may increase. This finding is also supported by studies using other markers of bone turnover. For example, increase in serum Alk-Ph was seen following 12 weeks of treadmill running exercise in aging ovariectomised rats [38], whereas decreases in urinary deoxypyridinoline concentrations following 90 days of treadmill running in rats have also been reported ${ }^{[39]}$. Similarly, in humans, lower serum 1CTP concentrations were found in runners who had been active in their sports for about 12 years when compared to their more sedentary controls ${ }^{[20]}$.

In our study, there were no significant changes in serum turnover markers with $8 \mathrm{STP}$ in young rats, however when the rats were further trained for additional 24 weeks after 8 weeks of exercise, significant changes in serum turnover markers were observed in some of the exercised groups with age. These results may imply that, maybe, a longer jumping duration is needed for eliciting discernable changes in bone turnover markers in the rats.

\section{CONCLUSION}

It appears that for maintaining the acquired gains in bone mass following 8STP, an exercise load of $30 \mathrm{~J} / \mathrm{w}$, i.e. $10 \mathrm{~J} / \mathrm{d}$ for $3 \mathrm{~d} / \mathrm{w}$, was the minimum level of continuous exercise load that was required after 8STP to maintain the 8STP-induced bone gains. It also appears that significant increases in bone mass in young rats following 8STP might not always be reflected by changes in serum levels of osteocalcin, Alk-Ph and 1CTP. However, measurement of these parameters, particularly 1CTP, might be more useful when evaluating the maintenance of bone gains after bone loading. While these findings suggest that bone mass and serum markers of bone turnover responded differently to jumping exercise in young rats, more measurements of bone responses at cellular level are needed to confirm our observations.

\section{ACKNOWLEDGMENTS}

This work was supported by grants from the Ministry of Science, Technology and the Environment, Malaysia (Project number: 06-02-05-2159 EA 009) and Universiti Sains Malaysia, Malaysia (Grant number: 304/PPSP/6131355).

\section{Conflict of interests: None}

\section{REFERENCES}

1. Christenson RH. Biochemical markers of bone metabolism: An overview. Clin. Biochem. 1997; 30: 573-593.

2. de Ridder CM, Delemarre-van de Waal HA. Clinical utility of markers of bone turnover in children and adolescents. Curr Opin Pediatr 1998;10:441-8.

3. Hart SM, Eastell R. Biochemical markers of bone turnover. Curr Opin Nephrol Hypertens 1999;8:421-7.

4. Umemura Y, Ishiko T, Tsujimoto H, et al. Effect of jump training on bone hypertrophy in young and old rats. Int J Sports Med 1995; 16:364-7.

5. Dalsky GP. Exercise: Its effect on bone mineral content. Clin Obstet Gynecol 1987;30:820-32.

6. Drinkwater BL. 1994 C.H. McCloy research lecture: Does physical activity play a role in preventing osteoporosis? Res Q Exerc Sport 1994;65:197-206.

7. Vuori I, Heinonen A, Sievänen H, et al. Effects of unilateral strength training and detraining on bone mineral density and content in young women: A study of mechanical loading and deloading on human bones. Calcif Tissue Int 1994;55:59-67.

8. Winters KM, Snow CM. Detraining reverses positive effects of exercise on the musculoskeletal system in premenopausal women. $J$ Bone Miner Res 2000;15:2495-2503.

9. Järvinen M, Kannus P. Femoral neck response to exercise and subsequent deconditioning in young and adult rats. $J$ Bone Miner Res 2003;18:1292-9. 
10. Pajamäki I, Kannus K, Vuohelainen T, et al. The bone gain induced by exercise in puberty is not preserved through a virtually lifelong deconditioning: A randomized controlled experimental study in male rats. J Bone Miner Res 2003;18:544-52.

11. Singh R, Umemura Y, Honda A, et al. Maintenance of bone mass and mechanical properties after short-term cessation of high impact exercise in rats. Int J Sports Med 2002;23:1-5.

12. Umemura Y, Ishiko T, Tsujimoto H, et al. Effect of jump training on bone hypertrophy in young and old rats. Int J Sports Med 1995; 16:364-7.

13. Honda A, Umemura Y, Nagasawa S. Effect of high-impact and low-repetition training on bones in ovariectomized rats. $J$ Bone Miner Res 2001;16:1688-93.

14. Umemura Y, Nagasawa S, Honda A, et al. High-impact exercise frequency per week or day for osteogenic response in rats. $J$ Bone Miner Res 2008;26:456-60.

15. Kim C-S, Park D-H. Effects of chronic $\mathrm{NH}_{4} \mathrm{CI}$ dosage and swimming exercise on bone metabolic turnover in rats. J Physiol Anthropol Appl Human Sci 2005;24:595-600.

16. Nishiyama S, Tomoeda S, Ohta T, et al. Differences in basal and postexercise osteocalcin levels in athletic and nonathletic humans. Calcif Tissue Int 1988;43:150-4.

17. Kristofferson A, Hultdin J, Holmlund I, et al. Effects of short-term maximal work on plasma calcium, parathyroid hormone, osteocalcin and biochemical markers of collagen metabolism. Int J Sports Med 1995;16:145-9.

18. Welsh L, Rutherford OM, James I, et al. The acute effects of exercise on bone turnover. Int J Sports Med 1997;18:247-51.

19. Hetland ML, Haarbo J, Christiansen C. Low bone mass and high bone turnover in male long distance runners. J Clin Endocrinol Metab 1993;77:770-5.

20. Brahm H, Strőm H, Piehl-Aulin K, et al. Bone metabolism in endurance trained athletes: A comparison to population-based controls based on DXA, SXA, quantitative ultrasound, and biochemical markers. Calcif Tissue Int 1997;61:448-54.

21. Matsumoto T, Nakagawa S, Nishida S, et al. Bone density and bone metabolic markers in active collegiate athletes: Findings in longdistance runners, judoists, and swimmers. Int J Sports Med 1997;18:408-12.

22. Karlsson MK, Johnell O, Obrant KJ. Is bone mineral density advantage maintained long-term in previous weight lifters? Calcif Tissue Int 1995;57:325-8.

23. Kontulainen S, Kannus P, Haapasalo H, et al. Changes in bone mineral content with decreased training in competitive young adult tennis players and controls: A prospective 4-yr follow-up. Med Sci Sports Exerc 1999;31:646-52.

24. Kontulainen S, Kannus P, Haapasalo H, et al. Good maintenance of exercise-induced bone gain with decreased training of female tennis and squash players: A prospective 5-year follow-up study of young and old starters and controls. J Bone Miner Res 2001;16:195-201.

25. Rautava E, Lehtonen-Veromaa, M, Kautiainen, H, et al. The reduction of physical activity reflects on the bone mass among young females: a follow-up study of 142 adolescent girls. Osteoporos Int 2007;18:915-22.

26. Shimamura C, Iwamoto J, Takeda T, et al. Effect of decreased physical activity on bone mass in exercise-trained young rats. $J$ Orthop Sci 2002;7:358-63.

27. Wu J, Wang XX, Higuchi M, et al. High bone mass gained by exercise in growing male mice is increased by subsequent reduced exercise. J Appl Physiol 2004;97:806-10.

28. Turner CH, Robling AG, Duncan RL, et al. Do bone cells behave like a neuronal network? Calcif Tissue Int 2002;65:466-71.

29. Holy X, Zerath E. Bone mass increases in less than 4 week of voluntary exercise in growing rats. Med Sci Sports Exerc 2000;32: 1562-9.

30. Kodama Y, Umemura Y, Nagasawa S, et al. Exercise and mechanical loading increase periosteal bone formation and whole bone strength in C57BL/6J mice but not in C3H/Hej Mice. Calcif Tissue Int 2000;66:298-306.

31. Umemura Y, Baylink DJ, Wergedal JE, et al. A time course of bone response to jump exercise in C57BL/6J mice. J Bone Mine Metab 2002;20:209-15.

32. Verhaeghe J, Thomsen JS, Bree RV, et al. Effects of exercise and disuse on bone modeling, bone mass, and biomechanical competence in spontaneously diabetic female rats. Bone 2000;27:249-56.

33. Souberbielle JC, Cormie C, Kindermans C. Bone markers in clinical practice. Curr Opin Rheumatol 1999;11:312-9.

34. Delmas PD. Biochemical markers of bone turnover. J Bone Miner Res 1993;8:S549-55.

35. Yarasheski KE, Campbell JA, Kohrt WM. Effect of resistance exercise and growth hormone on bone density in older men. Clin Endocrinol 1997;47:223-9.

36. Daly RM, Rich PA, Klein R, Bass S. Effects of high-impact exercise on ultrasonic and biochemical indices of skeletal status: A prospective study in young male gymnasts. J Bone Miner Res 1999;14:1222-30.

37. Ooi FK, Ismail N, Abdullah MY. Effects of combined aerobic dance exercise and honey supplementation on bone turnover markers in young females. Asian J Exerc and Sports Sci 2011;8:53-63.

38. Iwamoto J, Takeda $\mathrm{T}$, Ichimura $\mathrm{S}$. Effects of exercise on bone mineral density in mature osteopenic rats. J Bone Miner Res 1998;13:1308-17.

39. Horcajada-Molteni MN, Davicco MJ, Collignon H, et al. Does endurance running before orchidectomy prevent osteopenia in rats? Eur J Appl Physiol 1999;80:344-52. 